\section{THE VALUE OF CRITICAL CARE IN TRAUMA CENTERS}

\author{
M. Al-Sawwaf, A. Ayuyao, M. Parsa and H.P. \\ Freeman, New York, New York, U.S.A.
}

Surgical Critical Care Units in major trauma centers can prove life saving for the small number of severely traumatized patients who require admission to the Intensive Care Unit.

Harlem Hospital Center serves as one of eleven designated trauma centers in New York City. Analysis of trauma related data of this Center between January 1, 1985 to December 31, 1985 shows the following:

Total Trauma Related E.R. Visits

Total Trauma Related Hospital Admissions

Total Admissions to Surgical I.C.U.

Total Trauma Related Admissions to Surgical I.C.U.

\section{A TEACHING AND APPLICATIONS ALGORITHM FOR MEDICAL EMERGENCY MANAGEMENT IN DENTISTRY: THE HONG KONG MODEL}

\author{
T. Michael Moles, M.D., Hong Kong
}

Over the past decade increasing attention has been focused on the inadequacies of teaching and clinical care in the management of medical emergencies in dental practice. Excellence in conceptual and clinical training in basic and advanced life support is an exercise in applied logic and is therefore amenable to pictogrammatic presentation in the form of algorithms or flow charts.

A monoplex algorithm, based on the SAFE strategy devised and utilized in the Dental School in Hong Kong and incorporating the resuscitation procedures of the Resuscitation Council UK, has been developed and tested using a simple Apple II program. The algorithm illustrates clearly the logical sequence of responses required in an emergency and has proved a valuable tool for both first and second level inductive teaching, evaluation and clinical application for undergraduates, post-graduates and paradental personnel.

The rationale of design, application and evaluation of the algorithm will be presented.

\section{TRAINED TO HELP}

\section{Adriaan J.H. Korver, M.D., The Hague, The Netherlands}

logic status, which enables the physician to make an early detection of pathological developments hence
timely and appropriate correction of the abnormalities.

We believe proper and early utilization of the limited and extremely costly critical care facilities in trauma centers can prove life saving and therefore cost effective.
The Netherlands Red Cross developed its own training program for medical doctors in Red Cross disaster relief units. The program resulted from the very activities the Red Cross will have to perform in case of a disaster. We also made use of the knowledge and experience from other countries.

The training takes place under the supervision of experts in the field of resuscitology. In this way, the Netherlands Red Cross hopes to achieve the provision of emergency aid in everyday emergency situations and not only in the case of disasters. 